\title{
Five Currents of Organizational Psychology-from Group Norms to Enforced Change
}

\author{
I Niels Christian Mossfeldt Nickelsen' \\ Associate Professor, Danish Scool of Education, Aarhus University, Denmark
}

\begin{abstract}
This article discusses five currents in organizational psychology that have had particular signifcance in relation to the field of organizational development in Scandinavia: The social psychological, the socio-technical, the humanistic, the work psychological, and the social constructionist currents. I discuss central tenets from leading scholars in relation to group norms, contextualized working tasks, and conflicts among groups. Although treated differently, the phenomena of the small group, group dynamics, resistance to change, and process consultation are throughgoing. These phenomena link the discipline together into a mutually discordant, but relatively consistent discipline. While the early currents focused on interpersonal process based on dialogue for the sake of satisfaction and efficiency, the latter sees movement as a goal in itself.The analysis exposes a decrease over time of analytical interest in group norms, contextualized tasks, and avoidance of conflict. This focus on continual change has negative implications for the credibility of the discipline.
\end{abstract}

\section{KEYWORDS}

Organizational psychology / group dynamics / resistance to change / basic assumptions / relations / currents

DOI

10.18291/njw/s.v7il.81402

\section{Introduction}

rganizational psychology (OP) established early in the twentieth century and consolidated in the context of the two world wars and the great depression. In association with this, a number of empirical studies of working conditions and social relations in the workplace appear. One of the pioneers, Münsterberg (1913) aimed at sketching the outlines of a new science, which was to intermediate between laboratory psychology and everyday problems. He argued to bring the psychological science into the service of the working life. Another pioneer, Scott (1911), intended to make the workplace more efficient through the rationalization of worker activities, especially by appealing to the self-interest of laborers. His role in applied psychology eventually led him to be one of the founders of OP. The most comprehensive studies, the 'Hawthorne Experiments', took place in the 1920s and 1930s at the Western Electric Company in Chicago. It was not least through analyses of these by Roethlisberger and Dickson (1939) and Homans (1950) that an interest arose in norms and values in the small group. One became aware that networks among colleagues function as sets of norms for production ceilings, and

\footnotetext{
${ }^{1}$ E-mail: ncmn@dpu.dk
} 
mention was made of 'the human factor'. This became the foundation stone for OP as an independent discipline and its showdown with Taylor's scientific management (Scheuer, 2014; Taylor, 1911).

OP may be identified in relation to organizational sociology (OS) and organizational development (OD). OS is mainly an analytically driven apparatus that sees organizations as arrangements of elements, more or less successfully adapted to the larger context, determined to fulfill certain tasks through a system of coordinated division of labor (Scott \& Davis, 2007). In opposition to this, OP intends to overcome the dichotomies between analysis and intervention, and organizational behavior is seen as implicated by norms and values in the small group. It recurs in many central texts that OP is not a secluded academic discipline; rather advocates of OP have ambitions to treat practical problems in close collaboration with practitioners. Therefore, I argue, both theory and practice is constitutive of OP, and in this article, OP is analyzed as a theoretically warranted practical discipline.

OD, on the other side, appears in the literature as a cross-professional discipline drawing on psychological theory; ideas of involvement; group norms and values in order to promote planned change in organizations (for a good and recent overview see Burnes \& Cooke, 2012). In this article, exclusively a number of trends in OP that informs OD are discussed. This means I exclude reputable aspects of OP; I do not for instance offer work motivation, leadership, recruitment techniques, and issues related to the working environment the space it deserves (Hollway, 1991). OD theory and practice trace back to two events. The first is the publication of Lewin and Lippitt's autocracy-democracy studies. These showed that leaders who promote democratic participation obtained far better outcomes than autocratic leaders. Consequently, if autocratic leaders want to improve the performance of their followers, they need to change their own behavior. The second was the beginning of Lewin's long and extensive series of action research and participative management projects with the Harwood Manufacturing Corporation. These honed the tools, techniques, and approaches that became central to OD (Burnes $\&$ Cooke, 2012). I will discuss this further in relation to the social psychological current.

The acceleration of industrialization, increasing division of labor, and the need of recruitment principles were among the reasons that OP formed as an independent and relatively strong discipline. After the Second World War, a need arose with regard to the treatment of war trauma and the collective processing of the painful experiences from the Holocaust. How could it happen that civilized human beings could instigate such abhorrent atrocities? This question prompted an interest in a number of social psychological experiments, for example, the so-called conformity studies (Asch, 1951; Milgram 1974). In general, the interest in norms, values, and leadership intensified after the Second World War: How to solve social conflict? How do totalitarian regimes arise and civilizations break down? How can one develop democracy? It was from these questions that OP and OD gained momentum (Katz \& Kahn, 1966; Kozlowski, 2012).

In the following decades' bureaucracy, knowledge-intensive work, globalization, and public sector reforms led to new and intensified challenges in relation to leadership, flexible interactions, and lifelong learning (Aronsson et al., 2013; Näslund og Jern, 2015; Roe et al., 1994). In the '60s, '70s, and '80s, some interesting academic environments arose in London and Boston and these became, as I argue, crucial to what we today understand as OP. When the Berlin Wall fell in 1989, the grand narratives also dissolved (Lyotard et al., 1984) and the interest gathered around a new paradigm, social

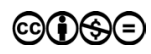


constructionism, and systemic consultation. This envelopment of certain overall societal tendencies contributes to explain why OP today appears as a variegated field of theories and methods.

\section{Design of the study}

My initial interest concerned the contribution of OP to the much broader research field of organization studies. By way of reviewing the OP literature and by taking a closer look at the principal arguments from leading scholars, I was soon able to crack down on five particularly influential currents: A social psychological; a socio-technical; a humanistic; a work psychological; and a social constructionist current. Kuhn (1962) suggested that a paradigm constitute a scientific discipline at certain point in time and that paradigms are discrete and culturally based. Drawing on Kuhn, I define a current as a scientific trend constituting a pattern of process and output over time. The currents I take up consist of clusters of theories and scholars that are apparent and dominant in Scandinavia between 1950 and 2010. The criteria of identifying the currents as significant and dominant are first, they are interconnected in the sense that the proponents refer to each other and recall a relatively consistent research field. Schein refer to Bion; Karasek refer to Trist \& Bamforth; Cooperider refer to Lewin and so forth. Second, they often appear in textbooks and are typically taught in subjects like 'human resource management'; 'organizational behavior' and 'personnel management' at universities and business schools. Third, they are practical and normative in the sense that they have things to say about practical problems in organizations. Fourth, they are well known and broadly accepted as influential in academia as well as in practice. Fifth, they can be classified as classics in the sense that they have enjoyed interest over a long period of time.

One can rightly argue for more and minor currents, for example, one with a focus on developing teams and team roles (Hackman, 2002; Katzenbach, 1998; Tuckman, 1965; West et al., 2003), and one with focus on leadership and motivation (EasterbySmith et al., 2002). Even though these have quite an importance in the English-speaking world, they have only gained a foothold in Scandinavia to a lesser extent. One can object that I give social constructivism a too prominent placing. Its prioritization is because social constructivism in the 1990s and '00s were particularly strong in research and practice in Scandinavia. In the English-speaking world, however, rather a cognitive/ behavioral current enjoyed a strong position (Hodgkinson \& Healey, 2008). Thus, the currents I present make up neither a complete nor an unequivocal description of OP. The classification of currents is not absolute or definitive. I use it here as a founding structure to create an overview of a number of more or less coherent theories, which, I argue, collectively constitute OP and which contain similarities across currents as well as incoherence (see Tab. 1).

On the basis of review of the literature, I argue, the notions of the small group, group dynamics, resistance to change, and process consultation link the discipline together into a relatively consistent research area. Despite articulated differently across currents, these phenomena, I argue, are through going tenets that glue the discipline together. By analyzing differences, I illustrate movements over time in OP and implications of this movement for the practical application of OP. The research question I focus on is; how does a number of currents shape OP during the 21 century and how has it changed? The 
Table I Five currents of organizational psychology

\begin{tabular}{|c|c|c|}
\hline Current & Central Authors & Central Notions and Tenets \\
\hline $\begin{array}{l}\text { The Social psychological } \\
\text { Current }\end{array}$ & Kurt Lewin & $\begin{array}{l}\text { Force field analysis, action research, group dynamics, } \\
\text { resistance to change }\end{array}$ \\
\hline $\begin{array}{l}\text { The Socio-technical } \\
\text { Current }\end{array}$ & $\begin{array}{l}\text { Albert Kenneth Rice } \\
\text { Eric Miller } \\
\text { Isabel Menzies-Lyth } \\
\text { Eric Trist }\end{array}$ & $\begin{array}{l}\text { The primary task, representation, boundaries and } \\
\text { social defense mechanisms, sentient boundaries, work } \\
\text { organization, technical organization }\end{array}$ \\
\hline The Humanistic Current & $\begin{array}{l}\text { Edgar Schein } \\
\text { Chris Argyris } \\
\text { Donald Schön }\end{array}$ & $\begin{array}{l}\text { Organizational culture, process consultation, artefacts, } \\
\text { espoused values, basic assumptions, defensive routines, } \\
\text { single loop learning, double-loop learning }\end{array}$ \\
\hline $\begin{array}{l}\text { The Work Psychological } \\
\text { Current }\end{array}$ & $\begin{array}{l}\text { Hans Selye } \\
\text { Robert Karasek } \\
\text { Töres Theorell } \\
\text { Richard Lazarus }\end{array}$ & Stress, coping, demand-control model, job design \\
\hline $\begin{array}{l}\text { The Social } \\
\text { Constructionist Current }\end{array}$ & $\begin{array}{l}\text { Gregory Bateson } \\
\text { Kenneth Gergen } \\
\text { David Cooperrider } \\
\text { Humberto Maturana } \\
\text { Tom Andersen }\end{array}$ & $\begin{array}{l}\text { Communication pattern, relation, language, appreciative } \\
\text { inquiry, reflecting teams, suitable disruption }\end{array}$ \\
\hline
\end{tabular}

procedure for analysis in reviewing the literature was to focus on different articulations of group norms, work tasks, and conflicts among groups. This draws on the understanding that good OP focuses on the reality of work itself. By way of this analytical procedure, I argue that the five currents expose a decrease over time of strict analytical interest in contextualized tasks and an increasing focus on providing reversing ready bodies for the sake of organizational change. This slide of focus means the initial focus on values and context of work transforms into a general socio-cognitive focus on systems change. This development, I argue, is both ethically and practically problematic.

\section{The Social Psychological Current}

Despite Kurt Lewin never saw himself as an organizational psychologist, he continues to be the most prominent figure in the discipline. He stated 'There is nothing as practical as a good theory'. He began his career as a gestalt psychologist in Berlin, but being born into a Jewish family, had to flee Berlin in 1933. Lewin ended up at MIT in Boston where he became absorbed in democratization and social change (Bargal, 2012, p. 34). He was interested in how to investigate psychological and social phenomena scientifically, not in the laboratory, but in 'the field' (Lewin, 1951). In the following, I discuss his contribution to OP in terms of group norms, work tasks, and conflicts among organizational groups. Lewins interest centered explicitly on group norms; how they establish, how they change, and how various forms of leadership contribute to this. While Lewin had little to say about work tasks, the notion of conflict, although indirectly, constitutes a central tenet. Due to the relative stability of group norms, group changes unavoidably involve conflict between group norms and the external force introducing change. 
Lewin's early research describes the dynamic interplay in 'life spaces', that is, the individuals experiential world. He wished to differentiate the way life space and the surrounding reality is anticipated by the person, thus he named the surroundings 'the social space', but unfortunately the precise relationship between the phenomenology of life space and social space was never clarified (Madsen, 2009). Due to the article, Frontiers in Group Dynamics (1947) published shortly before his death, Lewin became a pioneer in the formulation of group dynamics understood as psychological field dynamics in and between groups. His theory is a force field theory. A 'force field' is the interplay between driving forces and blocking forces (ibid, p. 308), and constitutes a balancing act between variously directed forces. Group dynamics and norms appear as results of such field dynamics; he argued (ibid, p. 305). The idea that a given force field may change via insightful analysis and the softening of influential forces is often associated with the influential idea in OD of planned change. 'Resistance to change', a term which would also prove to be of significant importance, is regarded as the mobilization of forces, which happens when an appreciated group norm is experienced as being in conflict with an external force (ibid, p. 327). By the notion of resistance to change, Lewin placed conflict as an unavoidable, although affordable aspect of changes within the group. A central assumption is that change requires softening of existing habits and norms. It was in Frontiers in Group Dynamics (1947) the well-known three-stage model of change saw the light of day 'Unfreeze, change and freeze'.

Although social forces are always in motion in a field over time, a temporary equilibrium between various forces establishes-a quasi-stationary balance of forces. Resistance occurs if there is an attempt to change this state of equilibrium toward the one side or the other. The more a force attempts to change the equilibrium, the more resistance occurs. If one wishes to change the field's condition, for example, the habits that have been established, it is consequently more expedient to reduce the forces contributing to the status quo being upheld, rather than increasing the pressure on them. Lewin showed via so-called involvement experiments, such as those linked to the shopping habits of housewives that group norms are better changed-or 'unfrozen'when they occur through the group's own discussions rather than when an attempt is made to affect them from an external source. Measured over the weeks following the completion of an experiment, and on the assumption of the same time and resources applied, the shopping habits of the homemakers were healthier after having discussed them in groups, than if they had merely attended a talk on healthy food habits alone. Lewin's analyses of his colleague Lippitt's tests with leadership in school classes is also wellknown. Together, Lewin et al. (1939) demonstrated that what he called the 'autocratic style of leadership' either entailed an extremely high or extremely low aggression level among children, while a 'democratic style of leadership' led to moderate aggression, and that the children worked longer on their own without support from an adult. In the 50s, numerous empirical studies made by Lewin's successors defined themselves within the ramification of group dynamics (Cartwright \& Zander, 1960). Through three decades, group dynamics with great inspiration from Lewin would be a constituent area of research in OP. The project on homemakers' shopping habits was a so-called action research project, intended to lead to desirable, and planned social changes. In action-research, the discussed field theory, group dynamics, and the value of democracy combines. Thus, in the perspective of the social psychological current group norms and the development of mutual confidence stands at the center of organizational change. 
Organizational change is in conflict with group norms; however, this conflict can be resolved. Thus, habits and norms must be mitigated as part of a interpersonal, egalitarian, and cooperative problem-solving process where the small group acts as the primary vehicle of change. This collaborative approach to create relevant principles of intervention is at the core of the social psychological current (Bargal, 2012, p. 41).

Lewin's detailed understanding of the interaction of conflictual forces seems to have been somewhat lost later on. At least, the term 'resistance to change' often appears as a superficial explanation with problems of change (Nielsen \& Svensson, 2006). From the social field level, 'resistance to change' transforms to an individual level and denotes an individual's malaise. To Lewin, it was limited to those forces in the field that arise in relation to the protection of appreciated group norms. Many studies of supervisory behavior in workplace settings still apply Lewinian concepts (Gilbreath \& Benson, 2004).

\section{The Socio-Technical Current}

\section{Work groups and basic assumptions groups}

The psychoanalyst Wilfred Bion (1961) carried out experiments and analyses of leaderless groups first, at the Tavistock Clinic in London and from 1946 at the Tavistock Institute of Human Relations. He developed an alternative group theory to Lewin's, which became a crucial source of inspiration for the socio-technical school. Bion was not himself a part of the socio-technical school, but inspired it greatly. In the following, I present Bions contribution to the socio-technical school mainly as an inspiration to the socio-technical school. Then comes a discussion of norms, tasks, and conflicts in relation to the socio-technical school and OP.

Bion focused on group dynamics as a system of behavior and processes occurring within a small group. With regard to this, he was particularly interested in the issue of group norms understood as collective fantasies. He studied group norms in relation to the question of authority in therapeutic groups (Bion, 1961, p. 101). ${ }^{1}$ Through group behavior, he separated two modes of existence, which are in conflict. As a rule, groups have a task, which makes collaboration necessary. In order to work on the task, the group must establish a rational contact with the surroundings, and similarly, it must have the means to organize appropriately around the task, which helps to contain frustration. Bion called this aspect the 'work group'. However, according to Bion, all groups are also from time to time experiencing fluctuating 'basic assumptions' of a regressive nature. While the work group is oriented toward the task of the group, the basic assumption group operates on a primitive fantasy level and occupies with elements that are not relevant for solving the task. Even though Bion observed in small therapeutic groups, a number of researchers argue that his observations are valid in organizations (e.g., Heinskou \& Visholm, 2011; Kets De Vries \& Miller, 1984; Schein, 1985).

Bion was not concerned with groups in the usual sense, but with modes of existence in groups. He identified three group aspects: a) the fight-flight group; b) the dependency group, and c) the pairing group (Bion, 1961, p. 105). The recurrent fantasy among members of the fight-flight group is that an enemy exists whom the group must engage 
or flee from. Emotionally, the group characterizes by anger, hate, and fear. The dependency group, on the other hand, builds on an idea that the group nourishes by the leader, without whom it feels defenseless, vulnerable, and worried. Finally, it is the controlling fantasy of the pairing group that one person or one idea will reveal itself, offering salvation and liberating the group from its fear, which is why the group uses a lot of energy on hoping for such possibilities. The group emotionally characterizes by hope, trust, and enthusiasm. In all three basic assumption groups, the assumptions are an expression of primitive defense mechanisms. No absolute distinction exists between the basic assumption groups. A group can flit between basic assumptions, just as it can fluctuate between work group and basic assumption groups (ibid., p. 129). Bion was interested in norms appearing as fantasies that either help or hinder the group to work on the primary task. Due to relational questions in groups, they may turn their back to the task by slitting into fantasies about authority, the leader etc. Conflicts in Bions perspective thus appear mainly between the challenge of goaldirected working on the task and prevention from doing so by fantasies.

\section{The Socio-technical School}

The term 'socio-technical systems' was coined by Eric Trist, Ken Bamforth, and Fred Emery based on their work with workers in English coal mines at the Tavistock Institute in London (1951). This was a beginning of an explicit interest in organizations in OP (not only in groups). At the same time, the primary locus of conflict was now between the technical-rational aspects and the human/social aspects of the organization. Furthermore, the notion of the 'primary task' allotted interest to what the organization was actually doing. In 1967, Eric Miller and Albert Kenneth Rice published the book Systems of Organization. This work together with the Scandinavian work environment experiments (Emery og Thorsrud, 1969) stand centrally in the socio-technical school. Moreover, an exemplary study by Isabel Menzies-Lyth (1975) constitutes an important socio-technical contribution. She studied rigid hospital systems as defenses against the anxieties raised by the practice of caring for seriously ill patients. By establishing a rigid hierarchy, fixed roles, and routinization of work, she argued, the hospital diffused responsibility and anxiety from the individual nurse to the system as a whole. That benefit however was shortsighted, she argued. The use of the primitive defenses of splitting, denial, and projection prevented mature forms of coping with anxiety to emerge, and thus stifled individual growth and caused many nurses to leave the profession. Miller $\&$ Rice found inspiration in this work and formulated an 'open system perspective' by joining together concepts from Bion's group analysis and system theory (Bertalanffy, 1976). The intention was to formulate a theory of work organization understood as dynamic in and between groups and not merely as dynamics in groups (as Lewin and Bion). At the same time, they were interested in the relation between social aspects and technology. The concept of a socio-technical system arose from the consideration that any production system requires both a technological organization and a work organization and that a work organization has social and psychological properties in terms of conventions, norms, and habits (Rice, 1958, p. 4). The thinking here is that the work organization is in conflict with the goal-oriented technical rational organization and this relation is to be mitigated and reconciled. 
Miller and Rice argue that organizations should aspire to 'sentient boundaries' (1990). 'Sentient boundaries' is an interesting notion that points to a satisfactory balance between the two partial systems seen from the perspective of the organization members. The assumption is that technical-rational work division ignores the psychological qualities of the work organization and therefore leads to dissatisfaction and low effectivity. In order to find such a balance, the organization must take its starting point in what the socio-technical school calls 'the primary task'. Rice defined this as 'the task the system must perform if it is to survive' (Dartington, 1998). The primary task is important in relation to investigating the prioritization of parts of tasks, and there can be variations over time and tensions between the various groups regarding what they regard to be the primary task. In their work as consultants, Miller and Rice, for example, worked on clarifying what the system in practice assumes as its primary task by advancing the interpretive statements in this way 'this institution acts as if its primary task was...' Later, these statements were compared with the explicit strategies of management that directed toward bringing together the organization on a common task. If disagreements arise over a longer period as to what the primary task is, then the organization is at risk to resort to the basic assumption mode of existence.

The terms 'representation' and 'boundary' played a central role in pinpointing the specific properties of work organization. An organization is an 'open system', which takes in material, humans, and information from its surroundings; inputs it, and transforms this input into an output. In addition, there are regulating activities (Miller \& Rice, 1967). With the help of this system of ideas the individual, the small group and the large group contemplates as increasingly complex extensions of this basic system. Each partial system has a 'boundary function' which controls what is 'inside' and 'outside'. The notion of boundary is interesting in terms of analyzing contact between departments within an organization. Each interaction between the groups implies a need for 'representation'. When representatives from several groups meet, new boundaries arise, and new sets of relations arise between the group of representatives and the units they represent. The groups may suspect the representatives of being loyal to the group of representatives and letting down the mandate-giving group. Inter-group activities may thus lead to new boundaries, norms, and conflicts (Miller \& Rice, 1975, pp. 60-61). By way of combining inspirations from psychodynamic group therapy and systems theory, the socio-technical school provided a consistent and impressive psychological theory of organizations. As it appears, the analysis and specificity of the primary task as well as the emerging conflicts between group norms and the technical-rational aspects of the organization stands centrally in the socio-technical current.

\section{The Humanistic Current}

This current draws on work developed at Harvard University and MIT in Boston on OD. Striking examples are process consultation, levels of organizational culture, and double-loop learning. The authors found inspiration in the human relations movement (Mayo, 1975; Scheuer, 2014). Although there are few references to humanistic psychology (Maslow, 1970), I call this branch of work the humanistic current because it testifies strong beliefs in the deliberate (although defensive) human actor. In the following, I discuss central works by Schein and Argyris and Schön in the light of group norms,

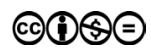


work tasks, and conflicts among groups. The arguments within this current are typically justified by normative models paving the way for a relatively harmonious betterment of organizational life. Group norms are indeed susceptible and conflicts are affordable. There is little focus on the specificity of work tasks. Rather the concerns are values, beliefs, and assumptions.

Edgar Schein is one of the top figures. His applicable concepts and models in relation to organizational culture and process consultation are widely adapted by companies and consultants, and his convincing work importantly contributed to the fact that $\mathrm{OP}$ in the end of the $80 \mathrm{~s}$ became an independent discipline at business schools and at psychology departments in Scandinavia.

In Edgar Schein's principal work Organizational Culture and Leadership (1985), one of the most influential management books, ever written, organizational culture is a pattern of beliefs learned by a group, as it solves its problems with external adaptation and internal integration. The book builts on the difference in the way Schein meets an American and a Swiss IT firm, respectively. In the former, Schein contributes immediately understandable and relevant, and he has difficulty finding space to communicate his words. In the latter, he addresses an attentively listening audience in white shirts and ties. Schein uses Bion's concepts, on basic assumptions to explain these cultural differences. Schein's model of organizational culture identifies three distinct levels in organizational cultures, artifacts, espoused values, and basic assumptions. The three levels refer to the degree to which these different cultural phenomena are visible to participants. Artifacts include tangible, overt, or verbally identifiable elements such as architecture, furniture, dress code, jokes and are the visible elements in a culture. Espoused values are the organization's written values and rules of conduct. It has to do with the way participants represent the organization both to themselves and to others. This often appears in public statements of values and identity. Trouble may arise if espoused values are not convincingly in line with tacit assumptions. Basic assumptions are the embedded, taken-for-granted behaviors, which are usually unconscious, but constitute the essence of culture. These assumptions typically integrate so well in everyday life that they are difficult to recognize by the group members. With regard to this latter point, Schein developed ideas on process consultation (1999). The 'process consultation model' is to be seen in contrast to the 'expert model' and the 'doctor model' as a collaborative model between people inside and outside the organization trying to understand and correct unintended interaction in order to improve collaboration. According to Schein, the central conflicts derive from the relation between the organization and its surroundings. The core challenge is to balance external adaptation with internal processes of integration and learning. With regard to this, the organization needs periodical correction of basic assumptions (norms) typically in relatively seamless dialogue with an external process consultant.

Another prominent figure is Chris Argyris, who in collaboration with Donald Schön has focused on organizational learning. With inspiration from the Deweyan concept of 'productive inquiry', they develop a theory of 'reflective practice' as a professional ideal. The reflective practitioner (Schön, 1983) observes and reflects on his own practice and gains the possibility of changing it or getting to know new aspects about it. In another central contribution, Organizational-learning 2 - theory, method and practice (Argyris \& Schön, 1996), the central ambition is to ensure better task performance. Under everyday time constraints, individuals will not be completely informed, nor 
do they have unlimited time to implement their actions. To operate within these constraints, humans uphold a master program (their theory-of-action) that informs them how to act. There are two kinds of theories-of-action: espoused theory-of-action made up by 'if-then' propositions that define effective action according to beliefs and values; and theories-in-use, which are the operating assumptions of actions that is detectable through observation. Although people hold their espoused theories dear, they rarely behave consistently with them, which is why it is the theories-in-use that is in the focus during organizational intervention. Individuals may or may not be aware of the discrepancies between their espoused theories and their theories-in-use. It appears that issues in peoples' theories-in-use make them unaware of these discrepancies, turning them into 'undiscussable' issues. It follows that human ignorance constitutes a program, and that eliciting this ignorance of humans' theories-of-action is a focal point in the humanistic current (Argyris \& Schön, 1996).

Further, all humans enact defensive reasoning and routines when threatened or embarrassed, and they cover this up by further defensive reasoning. This leads to a vicious circle that can only be broken through intervention aimed at installing awareness of how defensive routines act as a shield against feelings of threat (Argyris, 1990). Human ignorance of defensive routines is the problem to be defeated. The theories-ofaction that lead to this prevailing enactment of defensive reasoning are called Model 1 theories-of-action, which constitute barriers to Model 2 theories-of-action and, in turn, double-loop learning. Argyris developed various methods for working systematically with identifying and overcoming such defensive routines, for example, the 'left-hand column', which aims at promoting the leader's ability to communicate more openly via recognition of their own defensive reasoning and the crafting of confrontational dialogue (Argyris, 1998).

The crucial learning processes according to the humantistic current are to make a good fit between organization and environment by improved communication and capability to act. Argyris and Schön define two generic normative grounds for organizations: A defensive (model 1 theory in use) and knowledge spreading (model 2 theory in use) and ignore the specificity of norms and the problems and conflicts deriving from taks.

\section{The Work Psychological Current}

The work psychological current articulates an overarching conflict between a stressful environment and the individual's ability to cope. Certain job situations are stressful, while others are not. Further, a core tenet is that social support constitutes an important buffer in relation to cope with stress. In that sense, the current focuses both on the specificity of tasks and on group norms. However, the focus is on predefined constructs and measureability. The work psychological current in Scandinavia draws on biologist Hans Selye's conceptualization of stressors. By exposing mice to stressors, he showed this had a consistently negative effect on their health (Selye, 1950). This condition is 'the general adaptation syndrome' and forms the basis for the research of conditions that give rise to stress. The cognitively oriented 'coping' tradition (Lazarus \& Folkman, 1984) regarded the handling of stress as a psychological question. Here, it is the individual's cognitive response stress inducing, and the idea that with an appropriate coping strategy, one can reduce the strain. Another important contribution in this current is the placing 
Figure I Karasek's Demand-Control Model (1990).

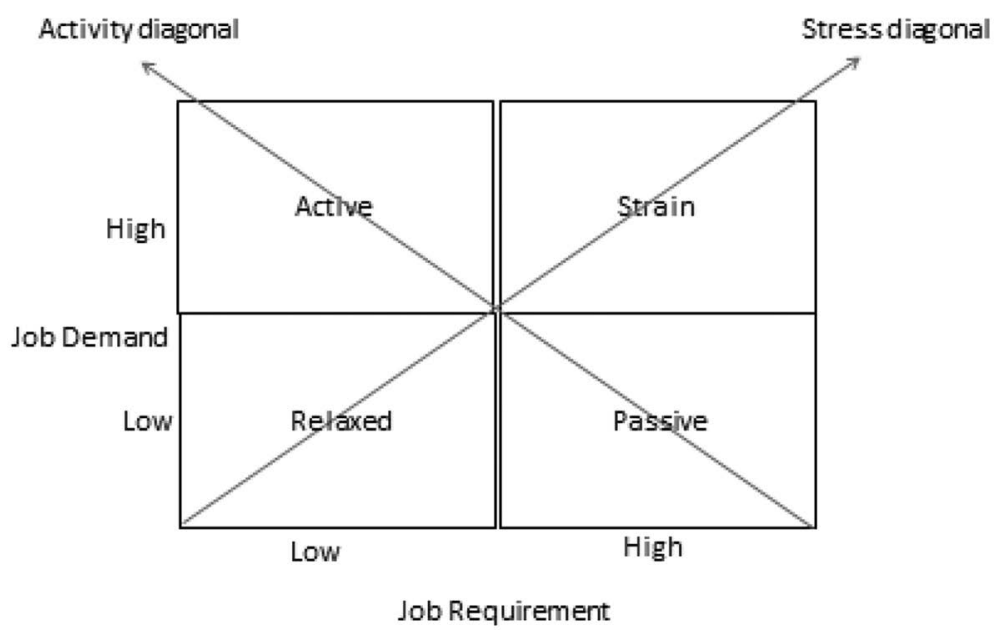

of models, which explains the connection between work conditions and stress. 'The demand-control model' (Karasek, 1979; Karasek \& Theorell, 1990) is used widely as a starting point for the conceptualization of stress (Agervold, 1998; Wegman \& Hogstedt, 2007). The model operates in its original form with two job aspects, namely demand and control (see Fig. 1) (Karasek, 1979), and has later been expanded with a third dimension social support (Karasek \& Theorell, 1990).

Karasek's demand-control model defines high stress and unhealthy jobs as those with low control and high demands. Low control includes unskilled labor and reduced decision-making capability. Employees in this position do not have the opportunity to make decisions concerning job content and methods of work. They also do not have the possibility to learn new skills on the job or alternative problem solving. High demand conditions include inadequate time to meet job demands and often an excessive workload. Karasek defines jobs and their stress levels by the demand-control combination. Active jobs, in the upper right quadrant, have high demands and high levels of control. These challenging jobs provide the opportunity to active learning and the possibility to develop new behavior. High strain jobs, in the lower right quadrant, have high demands and low control. These jobs have a high risk of psychological strain and physical illness.

Because of the alarming discovery that stress in the form of high demand and limited control can lead to cardiovascular disease, the model was widely spread. In its original form, it is conceived as an argument for promoting active and health-promoting jobs. This part of the theory builds especially on the Swedish and Norwegian experiences with democratized workplaces and the socio-technical school's argumentation that satisfaction and effectivity go together (Sandberg, 2007; Trist \& Bamforth, 1951).

Questionnaires on working environments are often associated with the demandcontrol model (Pejtersen et al., 2010). This type of questionnaire, though, is also inspired by other models, such as the 'Vitamin model' (Warr, 1987), the 'Effort-reward imbalance model' (Siegrist, 2002), as well as various coping approaches, such as the 'sense of coherence scale' (Antonovsky, 1987). These make it possible to measure and compare across 
contexts, professions, and branches. A widespread further development and nuancing of the demand-control model viewed from a Danish perspective is Kristensen's model 'The Six Golden Nuggets' 'Influence, meaningful work, predictability, social support, reward, and appropriate demand' (Iversen et al., 2002). This constitutes a broader collection of concepts than the demand-control model and therefore refers to a broader field of job attributes, which are widely accepted as being central in relation to deciding whether the job is damaging or edifying for the employee.

As mentioned, the work psychological current holds a strong position in research into the Scandinavian work environment and again what reoccurs is that dominant models operate with predefined positive aspects within work (control, development, meaning, democracy), and negative aspects (demands, stress, burnout, lack of influence), which one aims at promoting and preventing, respectively (Van der Doef \& Maes, 1999).

The work psychological current thus treats stress and well-being in a working environment as quantifiable conditions. What unify the theories of the work psychological current are the generic aspects, which no matter what job type presumes to be crucial for the working environment and well-being. This means there is after all little interest in the specificity of group norms, work tasks, and conflicts among groups. Norms, tasks, and conflicts appear exclusively as predefined and standardized constructs in order to be measureable (active jobs are good; high-strain jobs are bad etc.). This has given the perspective great influence in connection with consultancy, epidemiological research, cohort studies, quantitative studies of stress, bullying, absence due to illness, and the like.

\section{The Social Constructionist Current}

In the 1990s, social constructionism influences OP. The aim was to develop effective brief consultations and confront the grand narrative of psychoanalysis (Campbell $\&$ Huffington, 2008). Although social constructionism, systemic thinking, and appreciative inquiry clearly constitute quite different ontologies they merge in Scandinavia and during the 00 s together, they represent a strong and very influential coalition in OP gathered around a new focus on language and communication. In the following, I therefore treat them together as a social constructionist current. There is little if any explicit focus on the norms of organization members. Rather, focus is on how language constructs realities. The main challenge is by way of disruption to break communication patterns and pave the way for organizational change. There is no interest in the specificity of work tasks and jobs. It is all a matter of how you see and speak. Neither is there any focus on conflicts. Now, the focus is on appreciation.

The American social psychologist Kenneth Gergen came to be a considerable source of inspiration (1997). Gergen's work is associated with social constructionism and transformation of social life. He occupies with providing a relational view of the self where the emphasis on the individual mind exchanges with relational processes by way of which rationality and morality emerge. From Gergen's perspective, all knowledge claims generate within relationships. It is thus from relationships that humans derive their conceptions of what is real, rational, and good. From this point of view, reality does not appear in terms of truth, but in terms of pragmatic outcomes. The question is not accuracy, but potentials for humankind. The preferred direction of change is toward more collaborative relationships.




Inspired by cybernetics the American anthropologist Gregory Bateson became another prominent source of inspiration. Bateson argued that human intelligence appears as a systemic phenomenon and an effect of a system of cognitive and social relations and emerge as a number of differential operations (1972, p. 459). The aim was to move away from the enlightenment understanding of an inner sovereign subject and to understand human interaction in a communication paradigm, and focus on systemic patterns in the communication (ibid., p. 453). A number of formats developed to analyze such patterns of communication. For example, formulations of circularity, hypothesis formation, neutrality, and strategizing, such as differential identifying questioning techniques became widespread in connection with supervision (Tomm, 1989). The notion and practice of reflecting teams appeared in an article by the Norwegian social psychiatrist Tom Andersen (1987). He applied the above-mentioned questioning techniques. While interviews with groups with problems were carried out, the systemic and social constructionist observed the proceedings, identified differences, and disrupted existing systemic patterns of communications. Instead of talking about 'resistance to change', 'basic assumptions' or 'defensive routines' the interest now centered on 'differences', not on conflicts. The notion of 'autopoiesis' (Maturana \& Varela, 1987) showed itself to be useful in relation to nuancing the idea of ingeniously creating disturbances in locked communication patterns. For example, one speaks of establishing 'suitably unusual disruptions'. The individual ignores too many disruptions when the system is of one's own making. If the disruption conversely is 'too usual', it creates no tension and certainly no disruption. If the disruption, on the other hand, appears 'suitably unusual', it set changes in motion (Andersen, 2000, p. 63). The aim is to create reflective conversations, which contribute to nuancing understanding of a practice, which appears as stuck in operation. This is entirely a socio-cognitive approach and no mention is made of the reality of conflicts coming out of jobs or tasks. Rather, organizations constitute communication patterns that continuously have to be disturbed.

\section{Appreciative Inquiry}

'Appreciative inquiry' (AI) gained importance internationally in the '00s (Bushe, 2001, 2011) and it paved the way for the propagation of 'Positive Organizational Scholarship' (Cameron \& Spreitzer, 2011; Caza \& Caza, 2008). In later years, this perspective has gained favor in the USA, but has still only limited foothold in Scandinavia. Cooperrider and Srivastva expound the central challenge in AI like this 'AI appreciates the best of what is to ignite intuition of the possible and then firmly unites the two logically, caringly and passionately into a theoretical hypothesis of an envisioned future' (Cooperrider \& Srivastva, 1987, p. 165). They argue for a socio-rational revitalization of action research and acclaim Lewin for promoting democratic ideals, but criticize him for being inattentive to the negative effects, which focusing on 'problems' leads to (ibid., p. 131). On this account, a whole new dichotomy in OP is established; 'abundancy approach' versus 'deficiency approach' (Cooperrider et al., 2003). Focus should be on strengths and resources, not on weaknesses. Appreciative inquiry should appreciate that which is effective and focus on the best of 'what is', in order to create ideas about 'what could be' and with that comply with the future. Language creates the foundation of what is, ergo in the language lies an ethical challenge to focus on the best there is and place it in 
relation to the possible. To focus on deficiencies, for instance, strengthens conflict and self-fulfilling prophecy since language creates what it names.

The term 'heliotropism' connects to the early versions of AI. It is a biological term pointing to the fact that plants direct themselves toward sunlight. This metaphor illustrates that members in an organization turn toward visionary ideas. An assertion like this makes it clear that AI builds on naturalized ontological notions of a harmonic community. Cooperrider and Srivastva point out that appreciative inquiry supports and even creates common goals. It is precisely the 'common inquiry' of what already 'works' that has the potential to bring together divided communities in case of conflict. AI has increasingly been criticized for accommodating the risk of facts and critical information being omitted (Fineman, $2006 \mathrm{a}+\mathrm{b}$ ), a condition that involves the risk of the work group being blinded by the believed, but perhaps erroneous capability of the group (Janis, 1972).

\section{The notions of the small group, group dynamics, resistance to change, and process consultation}

Although the five currents are both internally and mutually discordant, there are also similarities across them pertaining to ways of understanding phenomena such as organization, group, and humans. The small group, group dynamics, resistance to change, and process consultation constitute recurrent and interconnecting notions and tenets. In this section, interconnections across currents are expanded further. In the the conclusion, some of the already mentioned breaches across currents and their implications are elaborated and specified.

Lewin's interest in the small group and indeed his pivotal tenet 'resistance to change' as a force that rise when appreciated group norms are challenged, constitute a recurring figure of thought that connect the five discussed currents. Bion contributed comprehensively to Lewins ideas on group dynamics by theorizing, not only group dynamics of force fields, but how particular modes of existence in the small group co-constitute basic assumptions, configurations of authority, and capability to act. Socio-technical researchers later took up Bion's ideas on basic assumptions and revitalized them by adding notions such as the primary task and boundaries, thus, not only focusing on the psychodynamics of the small group but also on intergroup processes among small groups in an organization. In doing so, Rice and Miller attended both the technical organization and the work organization aiming at promoting sentient boundaries, the dual goal of satisfaction among participants and organizational effectivity. As such the socio-technical current laid the foundation for the well-known collaborative Scandinavian approaches (Emery og Thorsrud, 1969) and the work psychological current's later emphasis on stress, demand and control as well as a long list of experiments accentuating self-managing groups and task variation (Sandberg, 2007).

Similarly, the humanistic current gathered inspirations concerning work motivation from the human relation school, Lewin's action research and Bion's ideas on basic assumptions (Schein, 1990, 1999, p. 30). The organizational culture's artefacts and espoused values are a kind of superstructure built on deeper lying and learned basic assumptions. The inspiration from psychodynamics is evident here. Moreover, the humanistic current gathered around process consultation in order to overcome or

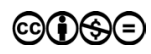


unfreeze defensive routines and negative assumptions by placing an emphasis on methods to create confrontational dialogue and collaborative interaction. This current of thought has undeniably been influential in relation to the thinking that participants are more or less stuck in problematic stable structures, operation systems, basic assumptions, and single loop learning and thus it has paved the way for almost limitless reflection. The point is that collaborative process and self-reflective learning by way of unfreezing inadequate assumptions may reorient groups to focus on adaptation and the demands of the surrounding world.

\section{Conclusion-from norms, tasks, and conflicts to enforced change}

The main argument is that OP spread over at least five significant currents from 1950 to 2010. Currents are scientific paradigms implying different processes and outcome. I have argued that OP alongside OD constitutes a relatively consistent, although disconcordant research field. I have argued that a number of throughgoing issues of interest characterize OP such as the small group, group dynamics, resistance to change, and process consultation, and I have argued that there are crucial similarities and figures of thought that occur again and again across the five currents, but important breaches also emerge specifically with regard to intentions and ethics. The latter are particularly the case after 1990. In this section, I conclude the article by a discussion of one particular breach that, I argue, has had profound implications for OP both as an academic and practical science.

For many reasons, the interest pertaining to group norms, work tasks, conflicts among groups was growing in the mulch of the interwar years and after the Second World War. The appearance of OP as an independent discipline relates to need for leadership, new collaborative industrial relations, job design, and the mutual adaptation between humans and machines. It was due to such essential societal challenges that OP developed into an influential academic and practical discipline. It should be evident from the preceding that the classic notions of OP: the small group, group dynamics, resistance to change, and process consultation, although articulated differently have been throughgoing and dominant focuses of interest. In contrast, during the last 25 years, these points of interest have been challenged. This pertains also the analytical focuses of this article; group norms, work tasks, and conflicts among groups. The analysis of five trends illustrate that the focus on these three issues has lessened over time by systemic and relational thinking. By way of language, relational, and systemic thought as well as intensified reflection, collaborative management provides a more complex understanding and viewpoint. The vision has been to create moving conversations that mobilize insight, pressure, and motivation and thus lead to new social and organizational action and realities. By accessing multiple interweaved systemic patterns, it is believed the small group is capable of disrupting defensive systems. This revitalization of thought constitutes undoubtedly not merely a new powerful action orientation, but also perhaps a less paternalistic framing of the tenet; resistance to change. The emergence of this figure of thought is typical for the time and still matches well with contemporary managerial-political demands on flexibility and constant reorganizing.

Thus, the growing engagement and demand from all kinds of organizations regarding intensified reflective practices is on one side a genuine success related to a century's 
attempts to involve employees in collaboration and dialogue. However, in a critical perspective, much points to the possibility that this latest budding in OP stand for a still stronger merger between political managerial discourses and the academic discipline of OP. Thus, OP appears increasingly embedded in managerial discourses intending rather, to discipline the small group and displace complexity from managerial levels to lower level participants, than genuinely to understand group norms, work tasks, and conflicts among groups. Much point at the possibility that reflective processes subtly intertwine with strong governance discourses and has growingly become an incontestable demand in everybodies working lives (Costea et al., 2008).

This critical reading of the social constructionist current leads to the question of what the shift from egalitarian dialogue targeting collaboration to enforced change based on intensified reflective processes imply in relation to the future of OP as a scientific discipline? While the early contributions were explicitly devoted to interpersonal process for the sake of democracy, satisfaction, and efficiency, the latter rather focus on involvement of organizational participants as part of an apparatus where break-up of locked communication patterns and continuous change appears to be the goal. As far as this analysis is correct, it is undoubtedly problematic with regard to the fineness of OP as a scientific discipline and for the general credibility of it. What was formerly a voice giving and progressive ambition has turned into a managerial project for the sake of adaptation, amelioration, and flexibility.

The discussion and analysis in this article of the five currents of OP and OD elucidates a gradual decrease over time of strict and thorough analytical interest in group norms, work tasks, and the conflicts among groups. Moreover, especially as the social constructionist current appears (and beginning with the humanist current), a general socio-cognitive approach seems to be promoted. This is an epistemology aiming at increasingly flexible groups, mindsets, and reversing ready bodies allegedly for the sake of intensified organizational change without much interest, neither in scrutiny of the values and specificity of jobs, nor in serious considerations and implications for the working environment. OP has in other words developed from an employee-oriented emancipatory discipline to a leadership science. A firmer ethics is in need if the former widespread credibility of OP is to be recaptured.

\section{References}

Aagaard Nielsen, K. \& Svensson L. (eds.) (2006). Action and Interactive Research - Beyond Practice and Theory. Maastricht: Shaker Publishing.

Agervold, M. (1998). Det psykosociale arbejdsmiljø, fra videnskabelig arbejdsledelse til arbejdsmiljøpsykologi (The psychosocial working environment, from scientific management to occupational psychology). Århus: Aarhus Universitetsforlag.

Andersen, T. (2000). Reflekterende processer - samtaler og samtaler om samtalerne (Reflective processes - talks and talks about talks). Dansk Psykologisk Forlag.

Andersen, T. (1987). The reflecting team: Dialogue and meta-dialogue in clinical work. Family Process, vol. 26 (4), 415-428. https://doi.org/10.1111/j.1545-5300.1987.00415.x

Antonovsky, A. (1987). Unraveling the mystery of health: How people manage stress and stawell The Jossey-Bass social and behavioral science series and the Jossey-Bass health series. San Francisco, CA, US: Jossey-Bass. 
Argyris, C. (1998). Teaching smart people how to learn. Harvard Business Review on Knowledge Management. Harvard Business School Press. Boston https://doi.org/10.1016/ b978-0-7506-7223-8.50015-0

Argyris, C. \& Schön (1996). Organizational Learning 2. Theory, method, and practice. Addison Wesley OD series. USA. https://doi.org/10.1177/103841119803600112

Argyris, C. (1990). Overcoming organizational defenses. Facilitating organizational learning. Allyn and bacon. Boston.

Aronsson, G., Hellgren, J., Isaksson, K., Johansson, G., Sverke, M., \& Torbjörn, I. (2013). 'ARBETS- OCH ORGANISATIONSPSYKOLOGI. Individ och organisation i samspel'. (Work and Organizational Psychology. Individual and organization in interaction) Bokförlaget Natur och Kultur. ISBN 978-91-2711905-5.

Asch, S. E. (1951). Effects of group pressure upon the modification and distortion of judgement. In H. Guetzkow (ed.) Groups, leadership and men. The Carnegie Press.

Bargal, D. (2012): Kurt Lewin's vision of organizational and social change - the interdependenace of theory, research and action/practice. In The Routledge Companion to Organizational Change (eds. Boje, Burness and Hassard). Routledge. London. https:// doi.org/10.4324/9780203810279.ch2

Bateson, G. (1972): Steps to an ecology of mind. Ballantines Books New York. https://doi. org/10.7208/chicago/9780226924601.001.0001

Bertallanfy (1976) General Systems Theory. Foundations, Development, Applications, New York: George Braziller, revised edition. https://doi.org/10.1126/science.164.3880.681

Bion, W. R. (1961). Experiences in Groups and other Papers. Tavistock Routledge. Bristol. https://doi.org/10.4324/9780203359075

Burnes, B. \& Cooke, B. 2012. Review Article: The past, present and future of organization development: Taking the long view. Human Relations, 65, 1395-1429. https://doi. org $/ 10.1177 / 0018726712450058$

Bushe, G (2011). Appreciative Inquiry. Theory and critique. In, Boje, D. Burnes, B. \& Hassard J (eds.) The Routledge companion to organizational change. London. Routledge. https:// doi.org/10.4324/9780203810279.ch6

Bushe, G (2001). Five theories of change embedded in appreciative inquiry. In, Cooperrider, D. Sorensen, P. Whitney, D. \& Yeager, T. (eds.) Appreciative Inquiry: Rethinking human organization toward a positive theory of change. Champaign IL: Stipes. https://doi. org/10.1108/lodj.2000.21.4.216.3

Cameron, K. S. \& Spreitzer, G. M. (2012). The Oxford Handbook of Positive Organizational Scholarship. The Oxford Psychology Library. New York. https://doi.org/10.1093/ oxfordhb/9780199734610.001.0001

Cartwright D and Zander A (1960). Group Dynamics Research and Theory. Evanston III. Row Peterson and Co. https://doi.org/10.1177/001789695401200406

Caza, B. \& Caza, A. (2008). Positive Organizational Scholarship: A critical theory perspective. Journal of Management Inquiry, Vol. 17 no. 8 pp. 21-33. https://doi.org/ $10.1177 / 1056492607305907$

Campbell, D. \& Huffington, C. (2008). Organizations Connected - A handbook of systemic consultation. Karnac Books.

Cooperrider, D. Whitney, D. \& Stavros, J. (2003). Appeciative Inquiry Handbook for leaders of change. Berret-Koehler Publishers. San Francisco.

Cooperrider, D. \& Srivastva, S. (1987). A Contemporary Commentary on Appreciative Inquiry in Organizational Life. Research in Organizational Change and development. Vol. 1. pp. 129-169. https://doi.org/10.1108/s1475-9152 (2013)0000004001

Costea, B Crum, N. Amiridis, K. (2008). Managerialism, the therapeutic habitus and the self in contemporary organizing. Human Relations, 61(5) 661-685. https://doi. org/10.1177/0018726708091763 
Dartington,T.(1998).FromAltruismtoaction:PrimaryTask and thenot-for-profit Organization. Human Relations, Vol. 51, no. 12. https://doi.org/10.1177/001872679805101204

Easterby-Smith, M. Thorpe, R. \& Lowe, A. (2002). Management research: An introduction. Sage Publications. https://doi.org/10.1177/135050769202300213

Emery, F. \& Thorsrud, E. (1969). Form and content in industrial democracy. Tavistock Publications. London. https://doi.org/10.2307/2094106

Fineman, S. (2006). On being positive: Concerns and counterpoints. Academy of management review. 31 (29) pp. 270-291). https://doi.org/10.5465/amr.2006.20208680

Fineman, S. (2006). Reply: Accentuating the positive? Academy of Management review 31(2) s.306-308. https://doi.org/10.5465/amr.2006.20208682

Gergen, K. (1997). Realities and relationships - soundings in social construction. Harvard University Press. https://doi.org/10.2307/2077591

Gilbreath, B. \& Benson, P. G. (2004). The contribution of supervisor behaviour to employeepsychological well-being. Work \& Stress, 18(3), 255-266. https://doi.org/10.1080/026 78370412331317499

Hackman, J. R. (2002). Leading teams, setting the stage for great performance. Boston. Harvard Business School Press. https://doi.org/10.2307/3556648

Heinskou, T. \& Visholm, S. (red.) (2011). Psykodynamisk Organisationspsykologi 2. På mere arbejde under overfladerne (Psychodynamic Organisational Psychology 2. On more work below the surface). Hans Reitzel.

Hodgkinson, G. \& Healey, M., 2008 Cognition in Organizations. Annual Review of Psychology. Vol 59, Issue 1. Januar 2008. https://doi.org/10.1146/annurev.psych.59.103006.093612

Hollway, W. (1991). Work psychology and organizational behavior - Managing the Individual at Work. London. Sage University Press. https://doi.org/10.4135/9781446280560

Homans, G. C. (1950). The Human Group. Hartcourt, Brace and company, New York. https://doi.org/10.2307/2572428

Iversen, L., Kristensen, T. S., Holstein, B. E., \& Due, P. (2002). Medicinsk sociologi: Samfund, sundhed og sygdom (Medical sociology: Society, health and disease). Munksgaard Danmark.

Janis, I. L. (1972). Victims of groupthink; a psychological study of foreign-policy decisions and fiascoes. Boston: Houghton, Mifflin. https://doi.org/10.2307/1917768

Karasek, R. (1979). Job Demands, Job Decision Latitude, and Mental Strain: Implications for Job Redesign. Administrative Science Quarterly, 24(2), 285-308. https://doi. org/10.2307/2392498

Karasek, R., \& Theorell, T. (1990). Healthy work. Stress, Productivity, and the Reconstruction of Working life. Basic Books. https://doi.org/10.1016/0003-6870 (92)90320-u.

Katz, D. \& Kahn, R. L. (1966). The Social Psychology of Organizations. New York. Wiley. https://doi.org/10.2307/2091895

Katzenbach, J. R. (1998). Teams at the top: Unleashing the potential of both teams and individual leaders. Boston: Harvard Business School Press. https://doi.org/10.5860/ choice.35-4591

Kets De Vries, M. F. R. \& Miller, D. (1984). The Neurotic Organization. Jossey-Bass. London. https://doi.org/10.1177/001872678403700201

Kozlowski, S. W. J. (2012). The Oxford Handbook of Organizational Psychology Vol 1+2. Oxford University Press. https://doi.org/10.1093/oxfordhb/9780199928309.001.0001, https://doi.org/10.1093/oxfordhb/9780199928286.001.0001

Kuhn, T. (1962): The Structure of Scientific Revolutions. Chicago. University of Chicago Press. https://doi.org/10.1086/ahr/68.3.700

Lazarus, R. S., \& Folkman, S. (1984). Stress, Appraisal, and Coping. Springer Publishing Company. 
Lewin, K. (1951). Field theory in social science. Selected Theoretical Papers. The University Chicago Press.

Lewin, K. (1947). Frontiers in Group Dynamics. Human Relations Vol. 1 Issue 1. https://doi. org/10.1177/001872674700100103

Lewin, K., Lippitt, R., \& White, R. K. (1939). Patterns of aggressive behavior in experimentally created 'social climates.' Journal of Social Psychology, 10, 271-299. https://doi.org/ $10.1080 / 00224545.1939 .9713366$

Lyotard, J. F. Benningston, G. Massumi, B. (1984): The Postmodern Condition: A Report on Knowledge. Minneapolis: University of Minnesota Press, 1984. https://doi.org/ $10.2307 / 1772278$

Madsen, B. (2009). Kurt Lewins modstandsbegreb - nærlæsninger, udvidelser og kritik (Kurt Lewin's resistance concept - close readings, extensions and criticism). Psyke \& Logos, nr. 2 Årgang 30.

Maslow, A. (1970). Motivation and Personality. Harper Books. New York. https://doi. org/10.1002/1520-6807 (197010)7:4\%3C410: aid-pits2310070426\%3E3.0.co;2-3.

Maturana, H. \& Varela, F. (1987). Kundskabens træ - Den menneskelige erkendelses biologiske rødder (Tree of Knowledge - the human knowledge biological roots). Forlaget Ask

Mayo, E. (1975). The social problems of an industrialized civilization. Routledge \& Kegan Paul. London.

Menzies- Lyth, I. (1975). A case study in the functioning of social systems as a defense against anxiety. In Group Relations Reader 1. Edited by Colman \& Bexton. An A. K. Rice Institute Series. Washington. https://doi.org/10.1097/00006199-196101030-00056

Milgram, S. (1974). Obedience to authority: An experimental view, Harper \& Row, New York, NY. https://doi.org/10.2307/2801239

Miller, E. \& Rice, A. K. (1990). Task and sentient systems and their boundary controls. I E. Trist, B. Trist \& H. Murray (eds.) 'The social engagement of social science' (vil. 1) Philadelphia: University of Pennsylvania. https://doi.org/10.9783/9781512819748-014

Miller, E. J. \& Rice, A. K. (1975). Selections from: Systems of Organization. In Group Relations Reader 1. Edited by Colman \& Bexton. An A. K. Rice Institute Series. Washington

Miller, E. J. \& Rice, A. K. (1967). Systems of Organization - the control of task and sentient boundaries. Tavistock Publications. London. https://doi.org/10.4324/9781315013947

Münsterberg, Hugo (1913). Psychology and Industrial Efficiency. Boston and New York: Houghton Mifflin Company. https://doi.org/10.1037/10855-000

Näslund, J. \& Jern, S. (red.) (2015). Organisationspsykologi (Organizational Psychology). Lund: Studentlitteratur. ISBN 978-91-44-09228-7.

Pejtersen, J. H. Kristensen, T. S. Borg, V. \& Bjorner, J. B. (2010). The second version of the Copenhagen Psychosocial Questionnaire. Scandinavian Journal of Public Health, 38(3. suppl), 8-24. https://doi.org/10.1177/1403494809349858

Rice, A. K. (1958). Productivity and social organization; the Ahmedabad experiment. Tavistock Publications. London. https://doi.org/10.2307/2550505

Roe, R. A., Coetsier, P., Levy Leboyer, C., Peiro, J. M., \& Wilpert, B. (1994). The teaching of work and organizational psychology in Europe: towards the Development of a reference model. European Work and Organizational Psychologist, 4(4), 355-365. https://doi. org/10.1080/13594329408410495

Roetlisberger \& Dickson (1939). Management and the worker: An account of a research program conducted by the Western electric company, Hawthorne works, Chicago. Harvard University Press.

Sandberg, Å. (ed.), (2007). Enriching production. Perspectives on Volvo’s Uddevalla plant as an alternative to lean production. Swedish Institute for Work Life Research. Stockholm, Sweden. Digital edition. Stockholm. https://doi.org/10.2307/2525104 
Schein, E. (1999). Process Consultation revisited Building the helping relationship. Addison Wesley.

Schein, E. (1990). Organisationspsykologi Organizational Psychology). Systime. København. Schein, E. (1985). Organizational Culture and Leadership - a dynamic view. Jossey-Bass.

Scheuer, S. (2014). Human relations-skolen (The Human-Relations School). I 'klassiske og moderne organisationsteorier' (redaktører Signe Vikkelsø og Peter Kjær. Hans Reitzels Forlag.

Schön, D. (1983). The Reflective Practitioner - how professionals think in action. Basic Books. USA.

Scott, R. \& Davis, G. (2007): Organizations and organizing: rational, natural and open systems perspectives. 1. Ed. Pearson Prentice Hall.

Scott W. D. (1911). Increasing human efficiency in business - a contribution to the psychology of business. The Macmillan Company. https://doi.org/10.1086/251987

Senge, P. (1990). The Fifth Discipline. New York. Doubleday. https://doi.org/10.1108/ eb025496

Selye, H. (1950). The physiology and pathology of exposure to stress: a treatise based on the concepts of the general-adaptation-syndrome and the diseases of adaptation. Journal of the American Medical association. Vol 144. Issue 16. https://doi.org/10.1001/ jama.1950.02920160088042

Siegrist, J. (2002). Effort-reward imbalance at work and health. Research in Occupational Stress and Well-being, 2, 261-291. https://doi.org/10.1016/s1479-3555 (02)02007-3

Taylor, F. (1911). The Principles of Scientific Management. New York Harper.

Tomm. K. (1989). Systemisk intervjumetodik - en utvekling av det terapeutiske samtalet (Systemic interview methodology - development of the therapeutic conversation). Mareld. Stockholm.

Trist, E. L. \& Bamforth, K. W. (1951). Some social and psychological consequences of the longwall method of coalgetting - an examination of the psychological situation and defences of a work group in relation to the social structure and technological content of the work system. Human Relations, 4, 3-38. https://doi.org/10.1177/001872675100400101

Tuckman, B.(1965). Developmental Sequence in small groups. Psychological bulletin, 63 (6), 384-399. https://doi.org/10.1037/h0022100

Van der Doef, M., \& Maes, S. (1999). The Job Demand-Control (-Support) Model and psychological well-being: A review of 20 years of empirical research. Work \& Stress, 13(2), 87-114. https://doi.org/10.1080/026783799296084

Warr, P. B. (1987). Work, unemployment and mental health. Oxford: Clarendon.

West, M. A. Tjosvold, D. \& Smith, K. G. (eds.) (2003). International Handbook of organizational teamwork and cooperative working. Chicheter, England. Wiley. https://doi. org/10.1002/9780470696712

Wegman, D. H., \& Hogstedt, C. (2007). Status report on Swedish work environment research-history, context and international evaluation. Scandinavian Journal of Work and Environment Health, 33, 1-53.

\section{Note}

${ }^{1}$ In Bion's work, the leader often appears as the analyst, which is Bion himself. This is, however, not always the case. In certain cases, the group ignores and devalues the analyst, and an alternative leadership appears. The leadership is not a person, rather fantasies on authority. 